\section{Resumen}

Los sujetos como productos y productores directos de una cultura específica y, por tanto, de una realidad histórica única construyen su ser en el mundo a partir una compleja gama de relaciones y rasgos identitarios; los cuales facilitan afirmar que abstracciones de la vida social como: la edad, la etnia, los roles sociales, la clase social, el sexo, el género y la orientación sexual de las personas terminan siendo definitivas en la configuración de dichas identidades y, por supuesto, de la forma como cada ser humano es concebido, valorado, reconocido e integrado al interior de su grupo social. En este sentido, el texto recoge una lectura de las categorías de exclusión e inclusión, a partir de las narrativas de un grupo de jóvenes constructores/as de paz habitantes de zonas de ciudades colombianas como: Cartagena, Manizales y Cali caracterizadas por la violencia generalizada, la reiterada vulneración y violación de los Derechos humanos y por estar involucradas en un proceso de formación y configuración de nuevas prácticas de participación políticaciudadana, desde la escuela como escenario de socialización.

\section{Palabras clave}

Exclusión, inclusión, participación, joven, reconocimiento

\section{Abstract}

Individuals as direct products and producers of a specific culture and, consequently, of a unique historical reality, build their own world from a complex range of relationships and identity traits. These issues allow us to state that abstractions from social life, such as age, ethnicity, social roles, social classes, sex, gender and people's sexual orientation, play a definite role in the configuration of such identities and, of course, of the way each human being is conceived, valued, recognized and integrated into the internal structure of the social group. Accordingly, this text interprets the exclusion and inclusion categories, from the narratives of a group of both male and female peace-constructing youths inhabiting various zones of different Colombian cities such as Cartagena, Manizales and Cali. These cities have a history of generalized violence, repeated infringement and violation of Human Rights and their citizens are involved in a construction and configuration process of new practices of political-citizen participation, which are born in the school as the socialization scenario.

\section{Key words}

Exclusion, inclusion, participation, youth, recognition 


\title{
Exclusión e inclusión: lectura de narrativas de un grupo de jóvenes constructores/as de paz ${ }^{1}$
}

\author{
Marta Cardona López ${ }^{2}$ \\ Julián Loaiza de La Pava ${ }^{3}$ \\ Héctor Fabio Ospina Serna ${ }^{4}$
}

Estoy deambulando entre dos mundos, uno de ellos muerto, el otro impotente para nacer.

(Arnold, 1855)

La investigación La escuela como escenario de socialización política: actitudes, sentidos y prácticas de participación ciudadana en jóvenes de estratos 1 y 2 de tres regiones del país, participantes en el programa nacional Jóvenes Constructores de Paz se realizó con el objeto de avanzar en el campo teórico de la socialización política y del análisis de los procesos de su constitución en jóvenes; a partir de actitudes, sentidos y prácticas políticas favorables a la democracia que fomentaran: su potencial

\footnotetext{
${ }^{1}$ Texto recibido el 21 de enero, evaluado el 12 y el 14 de mayo, y arbitrado el 9 de junio de 2008.

${ }^{2}$ Antropóloga, Diplomada en Derechos Humanos. Actualmente, estudiante del diplomado predoctoral: Investigación Crítica en Cultura del IPECAL de México y la Universidad de Caldas. Investigadora del Centro de Estudios Avanzados en Niñez y Juventud de la alianza CINDE-Universidad de Manizales. Integrante del Proyecto: Jóvenes Constructores-as de Paz. martacardonalopez@yahoo.es

${ }^{3}$ Licenciado en Educación Física y Recreación, Maestría en Educación y Desarrollo Humano (CINDE-Universidad de Manizales). Actualmente, estudiante del Doctorado en Ciencias Sociales, Niñez y juventud (CINDE-Universidad de Manizales). Investigador del Centro de Estudios Avanzados en Niñez y Juventud del CINDE y la Universidad de Manizales y Coordinador del Proyecto: Niños y Jóvenes Constructores de Paz. julipava@yahoo.com

${ }^{4}$ Licenciado en Filosofía y Letras. Magíster en Educación y Desarrollo Social. Doctor en Educación de la NOVA University-CINDE. Profesor Titular, Director de Tesis y de la Línea en Educación y Pedagogía del Doctorado en Ciencias Sociales, Niñez y Juventud del CINDE y la Universidad de Manizales. Director de la Revista Latinoamericana de Ciencias Sociales, Niñez y Juventud. revistacinde@umanizales.edu.co

${ }^{5}$ Investigación del Centro de Estudios Avanzados en Niñez y Juventud de la alianza CINDE- Universidad de Manizales, realizada entre el 2005 y el 2007, y financiada por Colciencias con el código: 123511-17686. Investigadores principales: Patricia Botero, Sara Victoria Alvarado, Héctor Fabio Ospina y Germán Muñoz; investigadores asistentes: Marta Isabel Gutiérrez, Julián Loaiza, Edwin Gómez, Juliana Torres, Jorge Eliécer Martínez, Diego Alejandro Muñoz y Marta Cardona López.
} 
humano, la reconstrucción del tejido social, el fortalecimiento de la sociedad civil y una alternativa de educación para la paz, viable y sostenible, que pudiera institucionalizarse y expandirse mediante el ejercicio permanente de los propios actores sociales.

En consonancia, el programa Jóvenes Constructores de Paz (JCP) es una propuesta, de carácter preventivo, que tiene como finalidad generar procesos participativos de jóvenes que promuevan la resolución pacífica de conflictos en espacios escolares, familiares y comunitarios en condiciones extremas de injusticia social. En esta medida busca promover en 1@s jóvenes una conciencia ciudadana para actuar como sujetos de transformación de sus vidas y comunidades, mediante el reconocimiento de sus capacidades de liderazgo y de estrategias como: la formación de pares (jóvenes que forman a otr@s jóvenes de sus instituciones educativas luego de ser formad@s y acompañad@s en un proceso integral de trabajo colectivo y acompañamiento a lo largo de dos años), y la multiplicación creativa del conocimiento en relación con cinco potenciales fundantes: afectivo, comunicativo, ético, resolución pacífica de conflictos y político.

Por tanto, el Programa contribuye a los procesos de paz en Colombia al creer en la construcción de ciudadanía, democracia y paz, a partir de la experiencia vital de jóvenes de diversas regiones del país; al expandir sus potenciales y construir procesos inéditos basados en sus voces, acciones e incidencia en la descolocación de prácticas sociales excluyentes; $y$, al generar pensamientos, conocimientos y herramientas que promueven el campo de educación para la paz y su diseminación.

Así, las siguientes cuartillas se aprestan a hacer una lectura de las categorías de exclusión e inclusión, a partir de las narrativas de un grupo de 120 jóvenes constructores/as de paz habitantes de sectores de tres ciudades colombianas: Cartagena, Manizales y Cali; sectores caracterizados por la violencia generalizada, la reiterada vulneración y violación de los Derechos humanos y por estar involucrados, desde algunas de sus Instituciones educativas, en un proceso de formación y configuración de nuevas prácticas de participación política-ciudadana ${ }^{6}$.

\section{Abordaje histórico de la categoría de exclusión}

Para nadie es un secreto que el devenir del mundo y de la vida, después de los horrores acaecidos en la primera mitad del siglo XX, ha exigido a la especie humana la adopción de otras lógicas de relación que, en su estructura fundante, recojan, promuevan y potencien el ejercicio permanente del cuidado conciente de la Otredad. En este sentido, y como un proyecto de responsabilidad ineludible, tampoco ha cesado de interpelar a académicos e intelectuales, sobre su rigor y compromiso a la

\footnotetext{
${ }^{6}$ La referencia participación política-ciudadana se toma como una categoría única, atendiendo a la definición construida por el grupo de investigación, el cual la comprende como: las acciones que afectan el orden social en su relación con el poder.
} 
hora de dilucidar los dispositivos sobre los que se erigió lo acontecido y, como tal, frente a las alternativas de creación y de acción desde las cuales se podría prever que lo pasado vuelva a suceder.

Así, como resultado, en gran medida, de la emergencia y acentuación de antiguas y nuevas prácticas de exclusión, desigualdad e injusticia, se comenzó a advertir una renovada preocupación en torno a los problemas sociales que afloraban. Como en otros momentos de la historia, el debate trascendió los límites de los ámbitos políticos y académicos y se ubicó en el centro mismo de la reflexión pública de las cuestiones sociales, dando paso al surgimiento de conceptos como el de exclusión social y a su actual relevancia cuando de pensar posible la construcción de un mundo mejor y diferente se trata.

A propósito, Lépore (s.f.) afirma que:

uno de los rasgos más destacados que asumió la extensión y difusión del mismo estuvo dado por un uso frecuentemente cargado de referencias indiscriminadas y confusas, que tendieron, en muchos casos, a revestirlo con abundantes connotaciones sociales, económicas, políticas y culturales. Si bien hay quienes ven en la versatilidad del lenguaje de la exclusión la presencia de ciertas ventajas ligadas a la capacidad de adaptación a los diferentes contextos, fue esa misma plasticidad lo que facilitó el desarrollo de una tendencia a designar casi indistintamente cualquier forma de privación con el rótulo de exclusión (p. 1).

El origen de la noción de exclusión social es relativamente reciente; según la literatura, la misma comenzó a ser empleada en Francia, a mediados de los años setenta, tras la publicación en 1974 de: Les exclus: un francais sur dix, texto escrito por Rene Lenoir, en aquel momento Secretario de acción social de su país. En tal publicación, Lenoir advertía que una décima parte de la población francesa podía considerarse como excluida: minusválidos físicos y mentales, sujetos con tendencias al suicidio, viejos inválidos, niños víctimas de abusos, adictos, malhechores, familias monoparentales, miembros de hogares con problemas múltiples, personas marginales y asociales, y otros inadaptados sociales (Silver, 1994). Población que, en todos los casos, hacía parte de categorías sociales carentes de protección social en un momento en que Francia andaba, precisamente, consolidando su sistema general de bienestar social.

Las razones que la hicieron común fueron dos fundamentalmente. Primero, porque fue utilizada por los republicanos en su discurso para contrarrestar la influencia del concepto de pobreza; el cual, no gozaba en el país de mucha simpatía, dadas sus vinculaciones al Ancien regime y al liberalismo utilitarista. Y, segundo, porque a mediados de la década de los ochenta fue recuperada para nombrar el conjunto de privaciones producto de los problemas sociales emergentes en el contexto de reestructuración económica y crisis del Estado de bienestar. Con esto, la 
noción de exclusión social pasó a ser tenida en cuenta para referenciar, no sólo los problemas del desempleo de largo plazo y recurrente; sino, también, la creciente inestabilidad de los vínculos sociales: familia y hogares monoparentales, aislamiento social y declinación de la solidaridad basada en los sindicatos, y mercados de trabajo y relaciones vecinales (Silver, 1994).

Una rápida mirada a la literatura reciente alcanza para evidenciar la extensa variedad de situaciones que se describen, a partir del discurso de la exclusión social; y, como, al igual que lo ocurrido con otros conceptos, ha llegado a referir tantos hechos y circunstancias que ha terminado por diluirse en todos los sentidos que se le ha dado: en definitiva, la noción está cargada tanto de sentido, como de sin sentido prestándose a interpretaciones erróneas cuando al ser forzada alude virtualmente a todo, incluso, a la decepción de quien no puede obtener lo que desea.

\section{Paradigmas de la exclusión social}

Frente a este aspecto, la lectura de los paradigmas propuesta por Silver (1994) continúa siendo efectiva a la hora de organizarse las diversas contribuciones empíricas y conceptuales sobre el tema. Según la autora, tres son las visiones más recurrentes en el análisis de la exclusión social: solidaridad, especialización y monopolio. Estas tres visiones o paradigmas resultan ser, en realidad, teorías de la sociedad y la exclusión que puntualizan diferentes causas y significados, pues:

cada paradigma atribuye la exclusión a una causa diferente, y se basa en una diferente filosofía política: republicanismo, liberalismo o democracia social. Cada uno ofrece una explicación para las múltiples formas de desventaja social económica, social, política y cultural, y así abarca teorías de la pobreza y el desempleo a largo plazo, la desigualdad racial y la ciudadanía (p. 609).

El paradigma de la solidaridad concibe la exclusión como una ruptura del vínculo social y un acto fallido en la relación entre la sociedad y el individuo que coloca en peligro latente la consolidación del cuerpo social. Desde este paradigma existe implícitamente un núcleo de valores y derechos compartidos, una comunidad moral, alrededor de la cual se construye el orden social, y una variedad de instituciones que aportan los mecanismos para integrar a los individuos a la sociedad.

El paradigma de la especialización entiende la exclusión como resultado de múltiples comportamientos e intercambios individuales. Según éste, las sociedades están compuestas de individuos con intereses y capacidades disímiles; mientras, la estructura de la sociedad se erige alrededor de la división del trabajo y de intercambios en las esferas, tanto económica como social. Los individuos pueden excluirse a sí mismos con base en lo que escogen, los patrones de intereses, las relaciones contractuales con otros actores, o como resultado de la discriminación, las fallas del mercado o de derechos que no se cumplen. La sociedad se ve compuesta por indi- 
viduos que participan en algunos campos y quedan excluidos de otros; por ello, la exclusión de un campo social no implica quedar por fuera de todos los campos.

El paradigma del monopolio asume a la sociedad de manera jerárquica; es decir, constituida por diferentes grupos, en manos de los cuales yace el control de los recursos; por consiguiente, los de adentro se protegen de los de afuera: construyendo barreras; restringiendo el acceso a ocupaciones, recursos culturales, y bienes y servicios; y, promoviendo lazos de solidaridad sólo con los suyos. Desde esta visión, la membresía en una sociedad es ineludiblemente desigual y las reglas que determinan el acceso a los grupos más privilegiados, también determinan la vulnerabilidad de quiénes quedan excluidos y, por supuesto, la construcción de su identidad: los mismos mecanismos pueden excluir a inmigrantes en una situación y analfabetos en otra. Para este paradigma, la exclusión actúa como un mecanismo que subyace en la estructura de la sociedad.

Estos tres paradigmas no agotan en modo alguno las diversas maneras en las que se puede conceptualizar la integración social, pero encarnan, no obstante, los principales modelos de aquélla; por lo tanto, deberían ser interpretados como tipos ideales, puesto que cada sociedad concreta está compuesta de una particular combinación de ideas que sustentan estos paradigmas (Lépore, s.f., p. 3).

\section{Configuración de la desigualdad y la exclusión}

Cuando de explorar la configuración de conceptos como la desigualdad y la exclusión se trata, resulta esencial admitir que desde la modernidad, las mismas se re-crearon con un sentido radicalmente disímil al que adoptaron en la antigüedad y el medioevo; pues, como consecuencia directa de la Declaración de los derechos del hombre y el ciudadano en 1789 , la historia comenzó a reconocer en la igualdad, la libertad y la ciudadanía principios emancipatorios de la vida en sociedad que llevaron a cualificar la desigualdad y la exclusión como excepciones o incidentes carentes de cualquier legitimidad. No obstante esto,

a partir del momento en que el paradigma de la modernidad converge y se reduce al desarrollo capitalista, las sociedades modernas pasaron a vivir de la contradicción entre los principios de emancipación, los cuales continuaron apuntando hacia la igualdad y la integración social, y los principios de la regulación, que pasaron a regir los procesos de desigualdad y de exclusión producidos por el propio desarrollo capitalista (Santos, 2003, p. 125).

Así, emancipación y regulación recogieron una díada de principios en constante pugna que terminó alimentándose de la misma tensión que generaba. Tensión que en la contemporaneidad sigue vigente gracias a lógicas y relaciones de poder que cada vez son más distantes e irreconciliables a razón de sus posturas y argumentos. 
Según Santos (2003) la desigualdad y la exclusión conforman dos sistemas de pertenencia jerarquizada. En este sentido, la pertenencia desde la desigualdad se da por la integración subordinada; en tanto que desde la exclusión se da por el sistema de exclusión. Dado que la desigualdad implica un sistema jerárquico de integración social, aquéll@s que ocupan los estratos más bajos de la sociedad, imprescindiblemente, hacen parte de éste, contrario a la exclusión en el que se pertenece por la forma como se es excluido: quien está abajo, está afuera. Aunque al ser enunciados, estos dos sistemas de jerarquización social aparecen como ideales, en la práctica, los grupos humanos se insertan paralelamente en los dos generando complejas combinaciones.

Consecuentemente, la desigualdad y la exclusión remiten a dos fenómenos que les son propios: el económico y el cultural, en tanto esferas de enraizamiento y expresión de sus lógicas; así, "si la desigualdad es un fenómeno socioeconómico, la exclusión es sobre todo un fenómeno cultural y social, un fenómeno de civilización" (p. 126). A propósito de las complejas combinaciones que pueden surgir cuando los grupos humanos se insertan paralelamente en los dos sistemas: desigualdad y exclusión, la modernidad capitalista facilita referenciar otras formas de jerarquización de carácter híbrido, como: el racismo y el sexismo, en las que se hacen evidentes elementos propios, tanto de uno como del otro.

Visto de esta manera, se puede abstraer que mientras que el sistema de desigualdades descansa, paradójicamente, en el esencialismo de la igualdad, puesto que el contrato de trabajo se da entre partes libres e iguales, el de la exclusión reposa en el esencialismo de la diferencia, avalado por: la cientifización de la normalidad y la prohibición o el determinismo biológico de la desigualdad racial o sexual. Con esto resulta oportuno agregar que es desde prácticas sociales, ideologías y actitudes puntuales de la vida cotidiana que las culturas hacen posible la mezcla entre: desigualdad, exclusión, pertenencia subordinada, rechazo y prohibición, configurando así, condiciones ideales para que un acoplamiento entre sistemas de desigualdad y exclusión se estructure, tal y como ocurre con el sistema de castas en India y la consecuente exclusión de los parias o intocables.

Como es de entenderse, entonces, desigualdad y exclusión permiten múltiples grados de expresión. Desde esta medida, el grado extremo de la desigualdad sería la esclavitud; mientras, el de la exclusión sería el exterminio o eliminación de la Otredad a razón de su diferencia radical, ejemplos de ello son: el genocidio de judíos y gitanos a manos del nazismo, durante la segunda guerra mundial, y, en la actualidad, la limpieza étnica que está en proceso.

En la misma lógica que desigualdad y exclusión aparecen acopladas como parte de la realidad local de sociedades afectadas por las contradicciones de la modernidad y su desarrollo capitalista, en el sistema global dos ejes de referencia también se cruzan: el eje socioeconómico de la desigualdad direccionado por la orientación Norte/Sur que constituye la expresión del imperialismo colonial y poscolonial, integrador de la diferencia; y, el eje cultural, civilizacional, de la exclusión direccionado 
por la orientación este/oeste que constituye la expresión de la frontera entre occidente y las civilizaciones orientales: islámica, hindú, china y japonesa. En este orden de ideas, la traducción más acertada del eje norte/sur resulta ser el imperialismo; en tanto, el orientalismo lo es para el eje este/oeste (Santos, 2003).

\section{Las paradojas de la igualdad y la diferencia}

En los contextos de la contemporaneidad, dispositivos de reconocimiento como la igualdad y la diferencia han sido rasgos fundamentales de las luchas de vindicación de los movimientos sociales y, por qué no, de la emergencia de nuevas subjetividades. De esta manera, como en un juego paradójico, unos y otros reclaman ser respetados en medio de la diferencia; al tiempo que exigen, desde la igualdad en derechos, condiciones y políticas de protección que aseguren su pleno acceso a una vida en dignidad. En otras palabras: ser reconocidos como iguales en la diferencia.

Ahora, si bien ésta es una de las lógicas desde la que se mueve, la disidencia y la resistencia en el mundo de hoy para contrarrestar los efectos de la desigualdad y la exclusión; también es importante advertir que el dispositivo ideológico de lucha de los sistemas de control imperantes sigue siendo el universalismo.

En este sentido, la ideología dominante en el Estado moderno es el universalismo antidiferencialista, a partir del cual, con discursos como: la ciudadanía y los derechos humanos se termina justificando la negación de todo particularismo; o sea, la esencia vinculante de la diferencia expresada en especificidades culturales; necesidades vitales; y microclimas simbólicos, regionales, étnicos, raciales o religiosos. Así, la exclusión se gestiona por la asimilación avalándose una amplia política de homogeneización y homogeneidad que, en general, comienza por la memoria lingüística; dado que, con la pérdida de ésta se asegura la perdida de la memoria cultural y, por consiguiente, de los sentidos, los contenidos y las prácticas que hacen realidad el espectro inagotable de la diferencia. Indiferencia desde la que se planifica y concreta el olvido histórico, el intervencionismo, la colonialidad del pensamiento, el poder dominante del miedo y, por supuesto, la eliminación de todo lo inédito (Santos, 2003).

Al respecto es esencial considerar que la compleja configuración y metamorfosis de los sistemas de desigualdad y de exclusión se da en medio de relaciones sociales bastante conflictivas, en las que intervienen grupos constituidos en función de factores como: clase, sexo, etnia, religión, región, ciudad, lengua, capital educativo y cultural, legalidad, grado de distancia frente a criterios hegemónicos de normalidad, etc.; factores que han jugado un eficaz papel discriminatorio en la jerarquía de pertenencia de ambos sistemas, según la época y la sociedad de la que se hable.

\section{Políticas de igualdad e identidad a la luz de la diferencia}

Ante la necesidad inminente de democratizar la participación y globalizar la justicia, el mundo de hoy se halla en la obligación de inventar nuevas formas de articulación 
entre políticas de igualdad y políticas de identidad. Como movimiento inicial urge entrar a hacer el ejercicio de reconocer que no toda diferencia es inferiorizadora $\mathrm{y}$, en esta dinámica, que las políticas de igualdad no tienen que minimizarse a una expresión identitaria única. Por el contrario, se requiere estar atentos para comprender que frente a diferencias no inferiorizadoras, las políticas de igualdad que las desconocen o descaracterizan se convierten, contradictoriamente, en políticas de desigualdad: una política de igualdad que niega las diferencias no inferiorizadoras es de hecho una política racista; pues, ésta se afirma tanto por la absolutización de las diferencias, como por su negación radical.

En este caso, una política genuina sería la que vehicule la articulación horizontal entre las identidades discrepantes y las diferencias en que éstas se fundan. De ahí que, según Santos (2003), un nuevo imperativo categórico

debe informar una articulación posmoderna y multicultural de las políticas de igualdad y de identidad: tenemos derecho a ser iguales cada vez que la diferencia nos inferioriza; tenemos derechos a ser diferentes cuando la igualdad nos descaracteriza. [...] El conocimiento y el reconocimiento de las diferencias presupone otro paradigma de conocimiento que $[. .$.$] tenga como punto de ig-$ norancia el colonialismo y como punto de conocimiento la solidaridad. En este paradigma, conocer significará seguir la trayectoria que va del colonialismo a la solidaridad. En esta trayectoria será posible no sólo reconocer las diferencias sino distinguir aquellas que inferiorizan y aquellas que no lo hacen, en la específica constelación social de desigualdades y de exclusiones en que estas diferencias existen (pp. 153-154).

Dado lo anterior, una política de identidad exigiría recrearse sobre el carácter transitorio de la identidad, en medio de un proceso concreto de identificación; pues, tanto las colectividades humanas como los sujetos experimentan, a lo largo de su historia, diversidad de identidades, de las cuales disponen, en cada momento, como mejor les place. Así mismo, explicarse, a partir de tres procesos básicos: diferenciación (separación entre el yo y el otro, entre nosotros y el resto); autorreferencia (momento especular de la creación de identidad, suma de las distribuciones originales que justifican una pertenencia específica e identitaria: mitos de orígenes, rituales, símbolos, orientación de valores e historia compartida); y, reconocimiento (reconocimiento del yo por parte del otro); no obstante la dificultad de demarcarlos desde los contextos y sistemas de desigualdad y de exclusión de la modernidad capitalista.

\section{Lectura de narrativas, visiones del comprender}

Hay una desproporción entre la experiencia y el relato, en la medida en que aunque los seres humanos quieren hablar y ser comprendidos, siempre se hace imposible 
reducir la distancia entre el lenguaje y la experiencia vivida. En esta ruta Benjamín (1998) relaciona la crisis de la experiencia con la de la narración, y ésta con la incursión de la información como forma de comunicación que, a diferencia de la narración, no requiere de la experiencia. Lo importante de esto es darse cuenta, hacer conciencia de que la narración, la experiencia narrada, vive en un proceso permanente de transmisión y que, en este fluir, el narrador o la narradora toma lo que narra de la experiencia, la que ha vivido por si mism@, o bien la que le han transmitido; pero, también, que sigue habiendo narración siempre que la experiencia vuelve a ser transmitida; pues si ésta no fuera comunicable, si no se transmitiera, la narración no sería posible.

$\mathrm{Al}$ respecto Benjamín dice que:

esta experiencia del narrador se torna, a su vez, en experiencia para el que escucha, para el oyente. El que escucha vive otra vez la experiencia. Y en este sentido, podríamos decir que el oyente (el lector) es capaz de recordar lo que no ha vivido, la experiencia que no ha experimentado, pero que le ha sido transmitida en el relato (p. 115).

En esta medida y compartiendo con Melich (2001) que "la memoria es el punto de partida de la ética. Una ética que no pretende dar testimonio "en lugar de otro", porque nunca se está en lugar de otro, sino de escuchar al otro, de dejar que el otro hable” (p. 26); el siguiente apartado recoge las voces de l@s jóvenes hecha narración en conversación hermenéutica con quienes acompañaron la pregunta rectora de la investigación tratando de vincular sentidos, preocupaciones y vivencias disímiles en una dinámica de reconocimiento de la afectación inédita del que narra.

\section{Escenarios, sujetos, tensiones y concertaciones}

Vivimos en un mundo donde los peligros creados por nosotros mismos son tan amenazadores, o más, que los que preceden del exterior. (Giddens, 2000, p. 47)

Los sujetos como productos y productores directos de una cultura específica y, por tanto, de una realidad histórica única construyen su ser en el mundo a partir una compleja gama de relaciones y rasgos identitarios' ${ }^{7}$ los cuales facilitan afirmar que

\footnotetext{
7 "Definir el concepto de identidad en esta nueva condición mundial implica un esfuerzo por comprender las prácticas simbólicas de la identidad, más que como rasgos descriptivos inmóviles, como elementos relativos a una red de relaciones sociales en movimiento, con lo cual se abre la posibilidad de proponer una interpretación más certera tanto de los mecanismos sociales a través de los cuales se recrea el orden cultural como de las contradicciones de dicho proceso" (Portal, 1991, p. 4).
} 
abstracciones de la vida social como: la edad, la etnia, los roles sociales, la clase social, el sexo, el género y la orientación sexual de las personas terminan siendo definitivas en la configuración de dichas identidades y, por supuesto, de la forma como cada ser humano es concebido, valorado, reconocido e integrado al interior de su grupo social. Por consiguiente, relaciones múltiples transversalizadas por lógicas de contacto y ejercicios de poder ineludibles definen la escala gradual de inclusión o exclusión, desde la cual l@s jóvenes sienten que pueden ser y hacer lo necesario para participar y decidir, de manera real, en la consolidación de sus entornos vitales.

Desde las narrativas de 1@s jóvenes, habitar el espacio de sus instituciones educativas conlleva poner en escena la construcción de una cierta clase de relaciones con 1@s demás; una suerte de códigos, acuerdos o normativas implícitas o explícitas que al recrearse develan circunstancias, acciones, presencias o ausencias de ciertos actores o actrices fundadas en lógicas de poder que al volverse ejercicios concretos de interacción, detonan sentidos y grados disímiles de exclusión e inclusión.

Así, retomando el concepto de Fraser (2002) de inclusión como la posibilidad de participación equitativa de las personas en todas las áreas de la vida, se puede aludir a la idea de los espacios de actuación de l@s jóvenes resaltando tres escenarios fundantes de su subjetividad: lo público, lo privado y lo íntimo. La posibilidad de estar y participar como alguien distinto exige entender que la vida misma no se da en una única esfera o en un sólo escenario; sino que, por el contrario, la complejidad de los seres humanos se da a partir de múltiples alternativas y, por tanto, en diversas esferas, en ninguna de las cuales se puede negar la esencia de ser diferente y reconocido a la luz de tal diferencia:

el requisito de la equidad participativa aplica en todas las áreas de la vida social. La mayoría de las sociedades tienen muchos campos distintos de interacción social, algunos de los cuales, determinan en gran medida la calidad de vida. Debido a que el acceso a estos es fundamental para el bienestar de las personas, es posible interpretarlos como 'esferas de justicia' [...] por consiguiente, el requisito de equidad participativa aplica en todas las esferas, pero la participación significa algo cualitativamente diferente en cada una (p. 60).

En este sentido, en escenarios públicos institucionales como: las emisoras radiales y los kioscos, considerados espacios de ocio, la participación de l@s chic@s emerge como un ejemplo de convivencia desde la pluralidad y la inclusión, toda vez que sienten que en estos se les garantiza acceso a los recursos existentes y, también, reconocimiento y respeto. Las emisoras radiales, como medio de comunicación y creación colectiva que expande posibilidades de interacción, son valoradas por su impacto en aspectos que van desde la libertad de decir lo que se piensa pasando por la formación académica hasta el hecho de poder escuchar colectivamente la música que más les gusta: 
la inclusión y la participación en la emisora me encantan; porque se expresan los sentimientos de todos los jóvenes, expresan sus ideas y las de los demás compañeros [...] En la emisora expresan sus sentimientos [...] Es la emisora de un colegio y se coloca música metálica [...] Aquí los jóvenes se preparan para el futuro [...] hay que mirar también lo educativo, ayuda a los jóvenes a prepararse para un futuro [...] se integran: hay una mejor integración de todos los jóvenes (Mujer, Cali).

Por su parte, frente a los lugares de consumo de alimentos como los kioscos se destaca la idea de que son espacios de relajación, unión y bienestar en los que tod@s pueden estar presentes: "en el kiosco [...] cuando salimos al descanso, nosotros los jóvenes nos integramos con algunos compañeros que tenemos en otros salones; abi compartimos ideas, la merienda. La tienda es un sitio de inclusión donde todos comen" (Hombre, Cali).

No obstante esto, si bien los espacios, escenarios o lugares de la vida de lo público se constituyen formalmente como espacios de la inclusión, tal constitución no equivale a decir que las lógicas de inclusión de las que se habla funcionen de manera cabal y homogénea, ajenas a condicionamientos, tensiones o prohibiciones que terminen sesgando los procesos de integración que son los que, finalmente, garantizan la participación plena y el reconocimiento consciente de los sujetos históricos como seres imprescindibles en la construcción de tales espacios y en la dinamización y transformación de sus lógicas de ocupación. De esta forma rasgos identitarios como el $\operatorname{sexo}^{8}$ y el género ${ }^{9}$ hacen la diferencia cuando se trata de hablar de escenarios formalmente incluyentes y aquellos que realmente conciben procesos integrativos más allá del simple gesto de incluir; pues, aunque las canchas suelen ser espacios de: lo público, el ocio y la inclusión; la forma, los ritmos y las acciones que definen su ocupación por parte de los sujetos sí varía dependiendo de si son mujeres u hombres.

\footnotetext{
${ }^{8}$ La especie humana simboliza un material fundamental que es idéntico en todas las sociedades: la diferencia corporal; es decir, el sexo. Así, aunque biológicamente se parta de la definición básica de dos sexos: hombre y mujer, las áreas fisiológicas que conforman el sexo biológico de una persona: genes, hormonas, gónadas, órganos reproductivos internos y externos (genitales) permiten pensar en la definición de otras combinaciones; pues, dichas áreas controlan cinco tipos de procesos biológicos en un continuum y no en una dicotomía de unidades discretas, cuyos extremos son el hombre y la mujer. Una clasificación rápida y aún insuficiente de estas combinaciones obliga a reconocer por lo menos cinco "sexos" biológicos: hombres (es decir, personas que tienen dos testículos), mujeres (personas que tienen dos ovarios), hermafroditas o herms (personas en que aparecen al mismo tiempo un testículo y un ovario), hermafroditas masculinos o merms (personas que tienen testículos, pero que presentan otros caracteres sexuales de una mujer) y hermafroditas femeninos o ferms (personas con ovarios, pero con caracteres sexuales de un hombre) (Grebe, 1993, pp. 339-340).

9 El género "alude al orden simbólico con que una cultura dada elabora la diferencia sexual" (Lamas, 1996, p. 332).
} 
-¿Qué pasa, por ejemplo en la cancha, cuando están jugando los hombres y llegan las mujeres y también quieren jugar?

-En el colegio hay dos canchas [...] no hay problemas.

-¿Qué pasa en los colegios en donde hay una sola cancha?

-Yo pienso que siempre se presentan muchos problemas; tanto que, a veces, las mujeres quieren darse una partida de voleibol y, como siempre, a los hombres les gusta a la mayoría la ruquita, abi vienen los problemas, las malas palabras, todo lo que genera la violencia entre hombres y mujeres [...] porque siempre se agreden mutuamente.

-¿Quién termina quedándose con la cancha para jugar?

-La verdad, siempre el hombre (Mujer, Cali).

Con lo anterior se comienza a vislumbrar que las situaciones de exclusión en las instituciones educativas se amarran a prácticas desde las cuales se expresa una inclusión que tiene en cuenta a tod@s, pero no como iguales. Bajo la lógica de una inclusión subordinada o marginada se estigmatiza a los sujetos y se les carga de cualidades como si fueran atributos naturales; se esencializa la existencia del otro o de la otra y se le marca con etiquetas como débil: en el caso de las mujeres y brusco: en el caso de los hombres, que terminan impidiendo una relación de equidad al validar que los hombres por ser más fuertes pueden imponerse sobre las mujeres; una lógica que induce a 1@s jóvenes a preferir separar los espacios de encuentro antes que a pensar en establecer alternativas de interacción en la diferencia:

en el colegio compartimos el tiempo: los hombres juegan determinado tiempo y luego entramos las mujeres y asi (Mujer, Cali).

Nosotras siempre nos golpeamos cuando estamos jugando [...] Por ejemplo, el profesor nos pone a hacer educación física y viene y coloca a las mujeres contra los hombres [...] Entonces, a veces, se nos hace más fácil, porque ellos al ver que nosotras somos así, cuando viene la pelota encima, uno se queda así, entonces le sueltan el balón a uno [...] Entonces es más fácil, no hay problemas (Mujer, Cali).

En las canchas de voleibol, las mujeres no dejan que los hombres jueguen voleibol y los hombres no dejan que las niñas jueguen fútbol en su cancha, los hombres no dejan que las mujeres juguemos alli (Mujer, Cali).

Como la marca biológica que es, la categoría sexo se erige en las narrativas de l@s jóvenes como una permanente de distinción; la cual, unida a las prácticas de género socialmente valoradas como masculinas y femeninas conforman un filtro, desde el cual se define, en gran medida, la aceptación, participación e ingerencia de cada un@ en escenarios específicos de la vida diaria. Ser básicamente hombre o mujer y comportar desde las normas y sistemas de valor culturalmente regulados 
conductas propias del sexo al que se pertenece, sigue siendo un parámetro definitivo a la hora de excluir o no a l@s demás.

De la misma manera que en las instituciones educativas, los espacios de lo público asociados al ocio se configuran desde la inclusión y la exclusión guardando una suerte de reglas de uso, en cuanto al momento y condiciones en que pueden o no ser usados por las personas de uno u otro sexo; se advierte otra clase de espacios como lo es el del conocimiento, el cual ubicado en la esfera de lo público y asociado a un derecho social de todo ser humano, como lo es el de la educación, se torna en un dispositivo claro y, por tanto, en un parámetro de discrepancia entre l@s jóvenes y entre ell@s y sus docentes:

en mi colegio [...] en mi salón [...] se pone en grupo a los que saben más y en horas de examen también; según los profesores que son vivos [...], pero que no lo son, ponen en una fila a los que no saben mucho y en la otra a los que saben, para que no se copien y no se fijen en los que saben. Pero no se dan cuenta que, de todas maneras, sí se fijan (Hombre, Cartagena).

L@s docentes, desde una figura simbólica de sujetos con supuesto saber, asumen la tarea de nombrar desde los sistemas de valor y de calificación imperantes, cuáles jóvenes cumplen con los requisitos necesarios para ser definidos o estereotipados como los que saben versus los que no: "en los colegios hay salones que son más avanzados que otros [...] de eso depende que uno esté en un salón y no en el otro" (Mujer, Cartagena). Por consiguiente, desde criterios estandarizados, negadores de la diferencia, 1@s jóvenes son rotulad@s, marcad@s y cercenados en sus posibilidades de ser y estar en el mundo; pues una sola lectura sobre sus potenciales cognitivos se erige como verdad y razón para que puedan ejercer su derecho de participar en plenitud:

otra cosa que se ve a diario en los salones de clase, en los salones cuando se está dictando un tema, es que un estudiante dice que es esto [...] no se que [...] $y$ aunque es un pelado que tiene más o menos idea de las cosas [...] hay otro que, supuestamente, es el superdotado y levanta la mano [...] y porque tiene la fama de tener idea, por eso siempre le dan la oportunidad (Mujer, Cartagena).

La distinción a causa de quién sabe más o menos es una coordenada de ordenación no sólo de salones, labores y ubicación de sujetos; sino, fundamentalmente, de relaciones de poder y reconocimiento de subjetividades, en la que también aflora la posibilidad de vincular a l@s jóvenes en gestos de solidaridad en los que la socialización ética del conocimiento y el fortalecimiento de los procesos de formación recogen y reconocen la decisión y pensamiento de 1@s mism@s chic@s: 
en mi colegio hay un grupito que sabe más [...] y si hay un grupo que sabe más hacemos grupos de cinco que se reparten y se van para los grupos de los que menos saben y comparten (Mujer, Cali).

En mi colegio a los alumnos que más se destacan les solicitan que se hagan con los que menos se destacan para que les enseñen y compartan sus conocimientos (Hombre, Manizales).

Otro escenario público que genera discriminaciones (positivas y negativas) ${ }^{10}$ y exclusiones de diversa índole es el de los baños; esto en razón de su inminente relación con el mundo de lo íntimo genital y, en consecuencia, por tener que ver con la estructuración simbólica de un territorio de poder radical como lo es el cuerpo. Un cuerpo que desde el arbitrio de la cultura ha sido semantizado desde el pudor, el pecado, el tabú, la negación, el castigo, etc., un cuerpo que ha sido marcado por signos y acciones consideradas coherentes a partir de prácticas sociales y sistemas de valor interesados en normalizar masculinidades y feminidades a la luz de una sola posibilidad: lo admitido versus lo prohibido.

- ¿Está bien que las mujeres no entren al baño de los hombres y los hombres al de las mujeres?

-Es una exclusión buena; porque, así, los hombres respetan un poco más a las mujeres (Mujer, Cartagena).

-Las mujeres dicen que cuando un hombre entra al baño de las mujeres es marica (Hombre, Manizales).

-Los baños no pueden estar pegados, porque hay mujeres que les encanta ver a los hombres orinar y a los hombres les encanta también ver a las mujeres (Hombre, Cali).

Desde un posicionamiento de reconocimiento frente a las diferencias; las narrativas de 1@s jóvenes hablan, también, de utilizar baños separados, porque entienden que biológicamente no son iguales: "los inodoros de los hombres son diferentes a los de las mujeres: un hombre no orina sentado en un baño y las mujeres no podemos orinar paradas o utilizar un inodoro para hombres” (Mujer, Cali).

\footnotetext{
10 "La acción afirmativa, término que se le da en los Estados Unidos a la discriminación positiva (Reino Unido), es una acción que, a diferencia de la discriminación negativa (o simplemente discriminación), pretende establecer políticas que dan a un determinado grupo social, étnico, minoritario o que históricamente haya sufrido discriminación a causa de injusticias sociales, un trato preferencial en el acceso o distribución de ciertos recursos o servicios así como acceso a determinados bienes, con el objeto de mejorar la calidad de vida de grupos desfavorecidos, y compensarlos por los perjuicios o la discriminación de la que fueron víctimas en el pasado. [...] El Comité para la Igualdad entre mujeres y hombres del Consejo de Europa define este concepto como las "estrategias destinadas a establecer la igualdad de oportunidades por medio de medidas que permitan contrastar o corregir aquellas discriminaciones que son el resultado de prácticas o sistemas sociales". (Wikipedia, s.f.).
} 
La resistencia por ganar un cuerpo libre de miedos y presto a una sexualidad para el respeto y el reconocimiento tiene que ver con la subjetividad y la subjetividad surge cuando es posible plegar la fuerza que se ejerce sobre 1@s otr@s en relación consigo mismo/a, tiene que ver con la ephimetea-hetau de los griegos, con la necesidad de darse un cuerpo, construirse un cerebro y darse un mundo; además, con las técnicas de sí y con las prácticas de la subjetividad cuya apuesta es el despojo del yo y del fascismo que se lleva dentro.

En este sentido,, como lo afirma Fraser (2002), para pensar las categorías de inclusión y exclusión se requiere tener en cuenta dos escenarios: por un lado, el escenario económico, el cual se centra en las posibilidades del sujeto para acceder a recursos económicos y materiales que le permitan una mejor calidad de vida; y, por otro lado, el escenario del reconocimiento que garantiza la participación y actuación en el mundo por parte de cada sujeto, desde sus diferencias en favor de la transformación de sus condiciones de existencia.

En algunos contextos, la exclusión social se ubica en el mismo campo general de conceptos como la pobreza y la inequidad. En otros, se acerca más a la negación del reconocimiento y a la falta de respeto, y aún en otros, forma parte del discurso sobre la desintegración y ruptura de los vínculos sociales (p. 55).

Por consiguiente, al entrar en discrepancia con el concepto hegemónico de inclusión que afirma que ésta sólo está determinada por el acceso a recursos económicos se comienza a entenderla en relación con el acceso a cualquier condición sociocultural; opción que facilita abordar el tema del reconocimiento de la diferencia (simbólica, étnica, atarea, sexual, etc.), también como una construcción política, como algo para pensar lo público en aras del bienestar personal y colectivo de los miembros de la sociedad.

\section{Ejercicios de poder y relaciones intersexuales}

¿Qué es un sujeto? Preguntaba hace poco en un curso, preguntaba para responder: el sujeto no es más que un conjunto

de hábitos a los que estamos acostumbrados. En cambio, la sujetivación sería la experimentación por fuera de nuestros hábitos. Es allí donde se abre un cambio de resistencia al poder. El poder en una micropolítica del poder no es algo por fuera de nosotros, el poder está dentro de nosotros mismos. (Garavito, 2000, p. 71)

En la historia de la sexualidad Foucault (1976) afirma que, sin duda: el poder no es una institución, una estructura o una cierta potencia de la que algunos estarían dotados; sino, el nombre que se asigna a una situación estratégica compleja en un 
momento dado. En esta dirección, no es posible hablar del poder como algo dado, que se adquiera, arranque o comparta, que se conserve o deje escapar. Este sentido usual, que atribuye el poder al Estado, a sus instituciones y aparatos o al sistema de dominación que un grupo ejerce sobre otro, es, en sentido estricto, una forma terminal de las relaciones de poder. Por consiguiente es más propio hablar de relaciones de poder y entender, en todo caso, que cuando se hace mención del poder, se alude a un conjunto de relaciones (procesos económicos, relaciones de conocimiento, relaciones sexuales, etc.) de fuerzas inmanentes y propias que se tornan conflictivas cuando se indaga por la forma cómo se ejercen.

Estas relaciones de fuerza, por su desigualdad, se encuentran en un continuo movimiento que induce estados de poder, en todo caso, siempre locales e inestables. Las estrategias que tornan efectivas las relaciones de poder se cristalizan en los aparatos estatales, en la formulación de la ley, en las hegemonías sociales, pero sobre todo en el cuerpo como primer territorio de poder y decisión humana.

Así cuando se habla de espacios de interacción asociados al mundo de lo privado o de lo restringido que, a su vez, entran a afectar el mundo de lo íntimo, 1@s jóvenes coinciden en manifestar que sus relaciones con personas del sexo contrario no son fáciles, ni carentes de prejuicios o condicionamientos de todo tipo. En el ámbito de la conversación se admite que sólo cuando el grupo de personas que está interactuando es de absoluta confianza: es decir, del mismo sexo, el diálogo se hace fluido y por fuera de restricciones que impidan que se exprese lo que se piensa con total libertad y honestidad.

-Cuando en los grupos de amigos, un grupo de hombres no deja que una niña hable con ellos [...] y las niñas cuando están en reunión de niñas no dejan entrar a los hombres y dicen: aquí están las monedas y no los billetes [...] mujeres, mujeres [...] hombres, hombres, ¿Cuál es el problema ahí?

-En las mujeres en parte, porque los hombres son como chismosos (Mujer, Cartagena).

$-¿$ ¿ómo así?

-Porque cuando ellos están hablando de las mujeres, dicen que no sirven para nada (Mujer, Cartagena).

En consecuencia, pareciera que la posibilidad de una conversación tranquila y sin exclusiones notables entre hombres y mujeres, sólo se establece cuando entre las dos personas de sexo contrario se ha establecido una relación amorosa que prefigura el conversar como un espacio de fortalecimiento de sus sentimientos:

supongamos que tú te sientas a hablar con tus amigas de tu novio, no te gustaría que pasara un hombre y se metiera a conversar o escuchar la conversación [...] Las mujeres siempre cambian de conversación cuando un hombre llega, de todas formas eso no le interesa a él (Mujer, Cali). 
Otras razones que bloquean el diálogo intersexual son los esquemas mentales afincados en sistemas de valor que desde aseveraciones, sin fundamento, llevan a una subvaloración o negación automática de los seres humanos en razón de su sexo. Al respecto Bourdieu (1989), plantea que la lógica del género es una lógica de dominación y de poder; es decir, una forma paradigmática de violencia simbólica, desde la cual se imprime violencia a otros con su complicidad o consentimiento. Según él, el orden social masculino se ha arraigado de tal manera que ya no requiere de justificación: hoy, se autoimpone como evidente y natural gracias al respaldo casi perfecto e inmediato, que recibe de estructuras sociales como la organización social del espacio, del tiempo y de la división sexual del trabajo; al igual, que de fuertes estructuras cognitivas inscritas en los cuerpos, mediante el mecanismo básico y universal de la oposición binaria.

-A veces es bueno entablar una conversación entre mujeres y hombres, porque se escuchan diferentes puntos de vista. En algunas situaciones, a veces no, porque los hombres quieren darse un porte (Mujer, Manizales).

-¿Cómo así que un porte?

-Se creen más que las mujeres [...] y, entonces, están hablando de las mujeres $y$ quieren saber más que uno (Mujer, Manizales).

No obstante esto, también es evidente que l@s jóvenes entienden la importancia de poder establecer comunicación permanente con l@s demás; pues en un mundo de diferencias, la única opción es aprender a convivir con éstas superando las lógicas de la exclusión. O sea, re-creando espacios y discursos de pertinencia en los que el poder de la palabra en relación con quien habla y quién escucha sea la manifestación de un ejercicio real de respeto al pensamiento disidente y al reconocimiento de la dignidad humana:

-Pero ¿es bueno o es malo que las mujeres no dejen entrar a los hombres y que los hombres no dejen entrar a las mujeres?

-Es malo, porque deben de relacionarse con todos (Hombre, Manizales).

\section{Roles sociales, identidades y diferencias}

La identidad, pensada desde la experiencia, se estructura sobre la pregunta ¿quién soy?, y ¿quién soy frente al otro? Sin embargo, para la comprensión cabal del proceso no basta el reconocimiento de la propia especificidad en contraste con el "otro". Es necesario estudiar cómo se construye y se recrea dicha especificidad.

(Portal y Aguado, 1991, p. 31)

Los roles sociales, y, en consecuencia, el estatus de las personas integran un rasgo de identificación que unido a escenarios puntuales y a ejercicios de poder transver- 
salmente efectivos denotan circunstancias precisas de inclusión y exclusión. Desde el rol de estudiante, pasando por el de rector/a, coordinador/a, docente, etc., l@s jóvenes entienden que su accionar y pertinencia en algunos espacios y escenarios de la vida cotidiana están mediados por las funciones o papeles que como actores y actrices desempeñan en la sociedad. El devenir en la institución educativa y la recreación de sus espacios de habitación están condicionados por normas y acuerdos que explícitamente prohíben o restringen el acceso y uso a cierta clase de personas en razón de sus roles sociales: rectoría, sala de profesores, coordinación, laboratorios, biblioteca y sala de informática generando una lógica que es vista o entendida como poco positiva por l@s jóvenes.

En consecuencia, cuando se retoman las narrativas de 1@s chic@s es posible discernir que en el espacio cotidiano de la vida escolar hay una serie de espacios físicos de acceso restringido que por hacer parte de una serie de lugares adscritos a funciones y personas puntuales; en los cuales, la presencia del público en general está reglada y controlada bajo argumentos institucionalmente establecidos, l@s jóvenes los leen como lugares de exclusión y negación de la pluralidad:

en la rectoría no entran todos los alumnos, alli sólo entra el que necesite algo [...] alli la exclusión es que a veces los profesores no nos dejan entrar, porque dicen que esos son espacios para los profesores; más bien, nos dicen que debemos esperar y preguntarles a ellos. En la sala de profesores nos excluyen, porque alli no dejan que todos los alumnos entren a hacer recocha (Hombre, Cartagena).

En el caso de la coordinación, aunque nombran que es un sitio muy positivo porque reciben ayuda y atención especial, lo definen como un lugar de exclusión porque sólo pueden habitarlo si tienen problemas: "en la coordinación les dan la oportunidad a los jóvenes de participar y expresar. Sin embargo, nos llevan sólo cuando hay problemas, alli se ayuda a los jóvenes" (Mujer, Cartagena).

De los laboratorios, algun@s piensan que son espacios que excluyen; dado que, no tod@s pueden entrar ni ocuparlos en cualquier momento: "a los laboratorios casi siempre entran son los alumnos de once grado, aunque en la semana científica entran todos a hacer sus experimentos" (Mujer, Cali). Pero, también existen l@s que admiten que algunas restricciones permiten la conservación de materiales e instrumentos delicados que sólo deben ser utilizados por personas preparadas para manejarlos: "sextos y séptimos ven química adecuada para ellos y no los dejan entrar, porque pueden partir algo o hacer daños" (Hombre, Cali).

Por su parte, si bien respecto a la biblioteca son explícitos en admitir que es un espacio de apertura total en el que lo que convoca es el conocimiento y la solidaridad: "a la biblioteca van todos a hacer tareas sin importar si son pequeños o grandes 
y tiene acceso la comunidad en un horario determinado" (Mujer, Manizales), no dejan de catalogarla como un escenario de exclusión; en tanto desde sus sentidos de la inclusión, los límites de horario de atención y las condiciones en que ésta se ofrece no satisfacen a cabalidad sus necesidades:

cuando los alumnos de la tarde van a hacer tareas en la mañana no nos dejan entrar, porque nos dicen que ese no es nuestro espacio, ya que debemos ir es en la tarde. En la tarde, la secretaria, la bibliotecaria se va a las dos o dos y media y no podemos hacer las tareas y, entonces, cuando tenemos el descanso a las cuatro y media para ir a hacer las tareas, ya no está ahí. Así que le pedimos el favor a la coordinadora que le extendiera más el trabajo, entonces cuando estamos en la tarde llegan los de la mañana y ellos si pueden (Mujer, Manizales).

-A ver, ¿cuál es el problema de que los de la mañana sí pueden entrar y los de la otra jornada no?

-Porque en la mañana, a veces, las profesoras de preescolar ponen a leer a los más pequeños y nosotros somos unos distractores para ellos, por eso no nos dejan entrar (Mujer, Manizales).

Frente a la sala de informática ocurre algo similar al entender como un mecanismo de exclusión, la restricción que implica no utilizar el Internet por fuera de las horas de clase estipuladas para tal menester:

la sala de informática es de exclusión, cuando no dejan que uno navegue en Internet o busque una tarea (Hombre, Cali).

-¿Quién no deja?

-La profesora, porque las investigaciones se deben hacer es cuando uno está en clase (Hombre, Cali).

En las construcciones de sentido que emergen queda la sensación de que l@s jóvenes superponen automáticamente discriminación (diferenciación) con exclusión, para ell@s hay una equivalencia entre no poder acceder a estos lugares y habitarlos con reglas, con la vulneración que produce cualquier ejercicio de exclusión apuntalado en la tiranía del poder. La posibilidad de pensar en una discriminación positiva o acción afirmativa que precisamente se haga realidad con el objeto de proteger los derechos de un cierto grupo de personas en razón de circunstancias especiales, pero sin afectar la vehiculación de los derechos del resto de los seres humanos, no es una idea que aflore o siquiera se insinúe en sus interlocuciones. 


\title{
Muros para cuidar, fronteras para excluir
}

\begin{abstract}
Para vencer el miedo, es preciso vencer antes la seducción que ejerce la esperanza de seguridad. Esto no implica, empero, abrirle las puertas a la resignación y la pasividad. Implica solamente la necesidad de decirle adiós a las ilusiones del progreso o, por lo menos, de someter sus promesas a una crítica severa, sobre todo cuando tienen lugar en un contexto político. La historia es el reino de la libertad y, por lo tanto, del peligro. En este sentido, el miedo es un compañero inseparable del ser humano. Sin embargo, de aquí no se sigue que sea necesario resignarse a vivir acosados por el miedo. La tarea es más bien, como sugiere Taussig, "despojar de su sensacionalismo al terror”.
\end{abstract}

(Ordóñez, 2006)

De la misma manera que la institución escolar aparece como un espacio de lo público en tanto expresión concreta de un habitáculo al que puede acceder todo ser humano como sujeto de educación; también es evidente que los colegios son lugares de acceso restringido cuando se habla de la seguridad de la comunidad educativa. Así, la seguridad se homologa a levantar fronteras, muros y límites que convierten el escenario educativo en una muralla que evita el encuentro, contacto o choque entre los de afuera y los de adentro. La protección se asemeja a encerrarse, aislarse, construir barreras y no puentes:

la pared es para que los alumnos no se vuelen y para impedir que entre cualquier persona de afuera (Hombre, Cartagena).

Requerimos de una pared que dé protección y sea más segura. Es una protección para los que están adentro [...] porque los de afuera no pueden tener una buena intención (Mujer, Cartagena).

Una mezcla de prejuicios y realidades endurece las fronteras y los mecanismos de cuidado; ejercicios de poder desde la dominación convierten territorios de saber en lugares de temor y no paso, potenciando un sentido de protección que apegado a las lógicas de la indiferencia alimenta la exclusión.

La realidad que aparece hace urgente e imprescindible desencializar el miedo, en aras de potenciar posturas vitales y novedosas que descoloquen el orden que convierte a 1@sciudadan@s en prisioner@s cotidian@s de sus propi@s vecin@s, calles y coordenadas de habitación. Como lo afirma Lechner (2000): "la preocupación por sobrevivir impide vivir. Para vivir, salir al encuentro de lo esperado, hay que exponerse" (p. 10). Y exponerse implica arriesgar, hacerle frente a las incertidumbres y optar por expandir y re-crear el ámbito de la vida cotidiana como espacio radical de lo político; hacer que los trayectos experienciales de los barrios, las calles y las 
esquinas se reconozcan como escenarios de la pluralidad, participación y dinamización de la democracia; insistir en que es desde tales espacios del día a día que la gente puede desafiar los imposibles de lo institucionalizado y, por tanto, decidir personal y colectivamente desaprender el miedo y abrirle de nuevo las puertas a la solidaridad, la amistad y la esperanza; conscientizarse de que se puede construir y heredar posturas frente al mundo que recojan múltiples miradas sobre la otredad y lo otro incorporando realidades no nacidas de la derrota, la repetición o la resignación.

\section{Ser y dignidad}

La igualdad, en sus múltiples manifestaciones -igualdad ante

la ley, igualdad de trato, igualdad de oportunidades-, es un derecho fundamental de cuyo respeto depende la dignidad y la realización de la persona humana. (Defensoría del pueblo, 2001, p. 12)

La estructuración de las identidades que devienen producto de las diferencias de sexo: hombre, mujer, etc.; género: masculinidades y feminidades, y rol, presentan una suerte de polaridades, pero también de rupturas que hacen pensar en un movimiento fluctuante hacia el equilibrio entre lo establecido y lo que puede cambiar; pues, 1@s jóvenes, de la misma manera que son conscientes de la importancia de acceder restringidamente a espacios como los baños, dado el reconocimiento de sus diferencias corporales y del respeto a la dignidad e intimidad del otr@; también expresan su rechazo ante los sistemas de valor que, en los ámbitos de lo cotidiano, instituyen privilegios para algunas personas en detrimento de la dignidad y derechos de 1@s demás:

cuando llega un profesor y hay una fila de estudiantes [...] atienden primero al profesor, asi no haga la fila o llegue de último. Nos dejan a nosotros ahi, atienden primero a una persona que acaba de llegar, abi se ve exclusión [...] Ellos también deben esperar su turno así como nosotros (Hombre, Cali).

Críticamente reflexionan acerca de las desigualdades que se establecen cuando, a partir de su rol, los seres humanos terminan siendo catalogados y tratados como personas de primera, segunda o tercera categoría. Al respecto precisan en favorecer condiciones que permitan que en toda sociedad se dé el reconocimiento pleno y particular de cada uno de sus miembros; pues, la posibilidad de participar a la par con otr@s en la interacción social implica el reconocimiento de una igualdad de estatus que promueva la desinstitucionalización de los patrones de valor cultural que limitan la paridad de la participación y la vindicación de múltiples concepciones de autorrealización o vida buena, a partir de la libertad y la justicia (Fraser, 2002). 


\title{
Normas y legitimidad
}

\author{
Así, perdido el Tao, queda la virtud \\ Perdida la virtud, queda la bondad \\ Perdida la bondad, queda la justicia \\ Perdida la justicia, queda el rito. \\ (Lao Tse, 1994, p. 21)
}

La elaboración del Manual de convivencia, como el conjunto de normas que rige la dinámica de la institución educativa, hace parte fundamental de los escenarios de la vida escolar de los que l@s jóvenes afirman sentirse excluidos; pues, no obstante ser estudiantes y tener derechos ineludibles al respecto, en general concluyen que su construcción, promoción y trascendencia se consolida sin su plena y masiva participación: "donde yo estudio a nadie le preguntaron algo para aportar al manual de convivencia” (Mujer, Cartagena). Así, las reglas de convivencia son dictaminadas sin la participación de l@s jóvenes, siendo directivas y profesores/as quienes de manera inconsulta y autoritaria las deciden.

De igual manera coinciden en que 1@s compañer@s que son representantes y tienen cargos de dirección eluden informar y consultar a sus compañeros sobre situaciones que afectan a tod@s, reproduciendo relaciones basadas en la verticalidad en las que el vínculo ético de responsabilidad y respeto por quienes l@s han elegido es ciertamente débil: "el personero cambia el manual de convivencia y no se preocupa porque los demás estudiantes conozcamos las nuevas normas. Él no publica las nuevas normas y no nos pregunta si estamos de acuerdo o no" (Hombre, Manizales). Total, lo que fluye no es una comunicación caracterizada por la apertura, la democracia o la participación; sino, por la exclusión en cuanto no reconocimiento de tod@s l@s integrantes de la Institución como sujetos políticos de decisión.

No basta con que se reconozca la posibilidad de acceso o participación de un grupo, es indispensable reconocer las particularidades de cada uno de sus miembros para entrar en un ejercicio pleno de la participación.

Lo que requiere reconocimiento no es la identidad específica de un grupo sino la posición de sus miembros individuales como socios plenos de derechos en la interacción social. Según esto, la falta de reconocimiento no significa el menosprecio y la deformación de la identidad de grupo. Más bien significa subordinación o exclusión social en el sentido de que se les impide a sus miembros participar como iguales en la vida social (Fraser, 2002, p. 62).

\section{Exclusión e inclusión desde las voces de I@s jóvenes}

-¿Qué es para ustedes la exclusión?

-Que no nos dejen participar en nada. Que nos rechacen. 
-¿Qué más es exclusión?

-Que haya diferencias.

-¿Qué quieres decir?

-Que en un grupo de estudiantes que están limpiecitos y bien presentados y de pronto se arrima alguien con la camisa sucia, abi mismo empiecen con la criticadera.

-¿Qué es la inclusión?

-Que nos tengan en cuenta. Todo lo contrario, donde todos pueden participar, estar; donde tengan en cuenta la opinión del otro, donde el otro hable sin importar su clase social, raza. Es como igualdad (Mujeres y hombres de Cali).

Para1@schic@s, el sentido radical de la exclusión pasa por la imposibilidad de participar; por el hecho de ser rechazados sobre la base de una diferencia que hace distinciones negando la expresión de lo diverso. Así, en esa misma medida, conciben la inclusión en relación directa con el reconocimiento y la participación, con condiciones que permitan opinar y plantear lo que se piensa; y, con una noción de igualdad que, pasando por la diferencia, viabilice la dignidad como rasgo ineludible de la esencia de todo ser humano.

\section{Reflexión desde la paz para continuar}

Aventurarse a plantear una investigación como la que circunscribe a este texto obliga a sus artífices a seguir preguntándose por el tema de la construcción de la paz desde otros órdenes; pues abordar la paz desde las perspectivas, lógicas, pensamientos y sentidos de1@sniñ@s y jóvenes, trae consigo un ejercicio de descolocación, en tanto obliga a sus gestores a asumir y elaborar la producción del conocimiento como una experiencia de superación del miedo y la ignorancia. Es decir, de aquellos obstáculos que Zemelman (2004) nombra como:

la ignorancia, el miedo, el miedo que nace de la ignorancia, la ignorancia que genera apatía, la apatía que genera aislamiento, el aislamiento que lleva a las personas a replegarse en sí mismas y a exaltar, a veces con pseudodiscursos teóricos, el repliegue a las relaciones primarias [...] ideologismos que no enfrentan el problema de fondo, que es el repliegue del individuo a sí mismo [...] una sensación de impotencia, una falta de fe en sí mismo, que se observa en la producción intelectual, repetitiva, que no innova ni descubre lo nuevo (p. 93).

Una producción de conocimiento que elude plantearse los problemas con claridad y, por consiguiente, rescatar a los seres humanos sin prejuicio, "como sujetos pensantes y actuantes, no solamente con capacidad de entendimiento, sino también con capacidad de tener una voluntad de conocer" (Zemelman, 2004, p. 93). 
Formar a alguien no equivale a imponerse sobre el sujeto. Por el contrario, a la luz del pensamiento libertario, significa entender al ser humano en el conjunto de sus dimensiones y habilidades, yendo más allá de la simple idea de desarrollar su inteligencia o su capacidad de procesar información. Formar pasa por potenciar la emocionalidad y fortalecer con decisión la voluntad que, a la larga, es lo que menos se atiende cuando se habla de arriesgar en esta dirección. Por tanto, lo esencial es resaltar que para crear una efectiva consciencia histórica, no basta con que las personas sean lúcidas o tengan una gran capacidad analítica; pues, el punto nodal de dicha consciencia tiene que ver antes que nada con la voluntad: con esa facultad de lo humano que hace que la persona se mueva y se enfrente con el deseo de ser sujeto, de transformar ese deseo en pensamiento lúcido y acompañar ese pensamiento con la construcción de discursos en los que se sienta incorporado y no ausente.

Por consiguiente, formar integra en su sentido problémico, la posibilidad real de activar al sujeto y propulsar sus ansias de ser un ciudadano pensante, un individuo con conciencia de las circunstancias de la sociedad en que vive y de sus propias posibilidades y límites: es mostrar la realidad, no solamente como una expresión de objetos; sino, fundamentalmente, como la concreción de espacios vitales en los que se hace imprescindible el despliegue de la subjetividad.

\section{Bibliografía}

Arnold, M. (1855). Stanzas from the Grande Chartreuse. Fraser's Magazine. http://rpo.library.utoronto.ca/ poem/106.html (consultado el 4 de febrero de 2008).

Bourdieu, P. (1989). Social space and symbolic power. Sociological theory, 7 (1), 14-25.

Benjamin, W. (1998). El narrador. (R. Blatt, trad.) En W. Benjamin (comp.).

Para una crítica de la violencia y otros ensayos. Iluminaciones IV (pp. 111134). Madrid: Taurus (trabajo original publicado en 1936).
Defensoría del Pueblo. (2001). Derechos humanos. El derecho a la igualdad. Bogotá: Defensoría del Pueblo.

Foucault, M. (1991). El sujeto y el poder. Bogotá: Carpe Diem.

FRASER, N. (2001). Informe mundial sobre la cultura 2000-2001. Diversidad cultural, conflicto y pluralismo. Madrid: Ediciones Mundi-Prensa-UNESCO. http://www.crim.unam.mx/cultura/informe/informe $\% 20$ mund2/capitulo2.html (consultado el 4 de febrero de 2008).

Fraser, N. (2002). Redistribución, reconocimiento y exclusión social. En 
Memorias del Seminario Internacional Inclusión social y nuevas ciudadanías. Condiciones para la convivencia y seguridad democráticas. Seminario internacional-memorias (pp. 55-69). Bogotá: Pontificia Universidad Javeriana-Alcaldía Mayor de Bogotá.

Garavito, E. (2000). ¿En qué se reconoce una micropolítica? Nova y Vetera, 41, 52-71.

GIDDEns, A. (2000). Un mundo desbocado. Los efectos de la globalización en nuestras vidas. Buenos Aires: Taurus.

Grebe, M. (1993). Antropología del género en la perspectiva del paradigma cognitivo simbólico. En S. Montecino. Huellas: seminario mujer y antropología, problematización y perspectivas (pp. 335- 350). Santiago de Chile: CEDEM.

LAMAS, M. (1996). El género: la construcción cultural de la diferencia sexual. México: Miguel Angel Porrúa.

Lao Tse. (1994). Tao Te King. Medellín: Grafoprint.

LeChNer, N. (2000). Hay gente que muere de miedo. Revista Desde la región 31, 4-11.

LENOIR, R. (1974). Les exclus: un francais sur dix. Paris: Seuil.

LÉPORE, E. (s.f.) Exclusion social: en busca de su especificidad conceptual. Buenos Aires, Universidad Autónoma de Buenos Aires, Fundación Observatorio social, pp. 1-19. http:// redadultosmayores.net/buscador/files/
ARGEN015_Lepore.pdf (consultado el 5 de febrero de 2008).

Melich, J. C. (2001). La ausencia del testimonio. Ética y pedagogía en los relatos del holocausto. Barcelona: Anthropos.

ORDÓÑEZ, L. (2006). La globalización del miedo. Revista Estudios Sociales 25, 95-103. http://www.scielo.org.co/scielo. php?script=sci_arttext\&pid=S0123885X2006000400011\&lng=es\&nrm= iso (consultado el 4 de febrero de 2008).

Portal, M. (1991). La identidad como objeto de estudio de la antropología. Revista Alteridades 1 (2), 3-5.

Portal, M. y Aguado, J. (1991). Tiempo, espacio e identidad social. Revista Alteridades 1 (2), 31-41.

SANTOS, B. (2001). Los derechos humanos en la posmodernidad. En M. Alonso y J. Ramírez. Ciudadanias y derechos bumanos sociales (pp. 167-184). Medellín: Escuela Nacional Sindical.

Santos, B. (2003). La caída del angelus novus: ensayos para una nueva teoría social y una nueva práctica política. Bogotá: ILSA-Universidad Nacional de Colombia.

Santos, B. y García, M. (2001). Colombia: el revés del contrato social de la modernidad. En Colciencias et ál. El caleidoscopio de las justicias en Colombia (pp. 11-84). Bogotá: Siglo del hombre Editores-Universidad de los AndesUniversidad Nacional de Colombia.

Sarmiento, L. (2004). Ciudadanías y políticas públicas inclusivas e integra- 
les. En F. Carrillo. Ciudad e inclusión: $\quad$ Buscar\&lr= (consultado el 4 de febrero por el derecho a la ciudad (pp. 83-107). de 2008).

Bogotá: Fundación Foro Nacional por Colombia-ATI-Fedevivienda- Corporación Región.

WIKIPEDIA. (s.f.) http://es.wikipedia.org/ wiki/Acci\%C3\%B3n_afirmativa (consultado el 4 de febrero de 2008).

SILVER, H. (1994). Exclusión social y solidaridad: tres paradigmas. Revista internacional del trabajo 113 (5-6), 607-662. http://scholar.google.com.co/ scholar?hl=es\&lr=\&q=revista+internac ional+de+trabajo.+113.+1994\&btnG=

Zemelman. H. (2004). En torno de la potenciación del sujeto como constructor de la historia. En DIUC-Universidad Central. Debates sobre el sujeto. Perspectivas contemporáneas (pp. 91-104). Bogotá: Siglo del Hombre Editores. 